\title{
Tradição oral e tradução: a comunicação intercultural e as dificuldades para a tradução-versão dos provérbios entre o português brasileiro e o italiano
}

\author{
Alcebiades Arêas ${ }^{1}$ \\ Universidade do Estado do Rio de Janeiro \\ bideareas@gmail.com \\ Edvaldo Sampaio Belizário ${ }^{2}$ \\ Universidade do Estado do Rio de Janeiro \\ edvambel@bol.com.br \\ Maria Aparecida Cardoso Santos ${ }^{3}$ \\ Universidade do Estado do Rio de Janeiro \\ cardoso.aparecida@gmail.com
}

RESUMO: Os provérbios fazem parte da cultura e do folclore de um povo e são passados de geração em geração, diretamente, por meio da palavra. Por fazerem parte da tradição oral de um povo, os provérbios transmitem conhecimento e ensinamento sobre os mais diversos aspectos da vida. Além disso, são fundamentais na consolidação de valores morais e princípios de convivência social, por conterem conselhos e admoestações visando a indicar modos para os homens conviverem e agirem de maneira cordial e respeitosa. Em outras palavras, provérbios, sentenças, aforismos e máximas, dentre outros, possuem grande valor didático-pedagógico, fixando-se na memória e atuando como um código de conduta. A forma concisa, a estrutura simples e a facilidade de compreensão das mensagens contidas nos provérbios permitem que suas fórmulas sejam memorizadas e transmitidas com grande facilidade entre povos e culturas de geração em geração. Uma característica importante das construções proverbiais é o seu caráter de universalidade, que não pode ser limitado por barreiras sociais, ideológicas ou geográficas. A capacidade de repetição e de atualização dos provérbios confere importância ao seu estudo, seja por enriquecer as pesquisas em tradução, seja por sinalizar a outros pesquisadores que existe muito a ser feito nesse campo. Neste artigo, além de retormarmos o conceito de provérbio, sua origem, suas variações e seu deslocamento semântico no tempo e no espaço, vamos apresentar uma

\footnotetext{
${ }^{1}$ Doutor em Letras Neolatinas pela UFRJ. Atualmente, é Professor Associado de Língua, Literatura e Cultura italianas da UERJ.

${ }^{2}$ Mestre em Literatura Italiana pela USP. Atualmente, é Professor Assistente de Língua, Literatura e Cultura italianas da UERJ. È doutorando em Estudos Literários: Literatura Italiana na UFRJ.

3 Doutora em Língua Portuguesa pela UERJ. Atualmente, é Professora Adjunta de Língua e Cultura italianas da UERJ.
} 
Tradição oral e tradução: a comunicação intercultural e as dificuldades para a tradução-versão dos provérbios entre o português brasileiro e o italiano

Alcebíades Arêas

Edvaldo Sampaio Belizário

Maria Aparecida Cardoso Santos

proposta para traduzi-los no contexto linguístico-cultural das línguas portuguesa, variante brasileira, e italiana.

Palavras-chave: Provérbios. Cultura. Tradição Oral. Proposta de Tradução.

ABSTRACT: Proverbs are part of the culture and folklore of a people and are passed on from generation to generation, directly, through the word. Proverbs transmit knowledge and teaching about the most diverse aspects of life, as they are part of a people's oral tradition. In addition, they are fundamental in the consolidation of moral values and principles of social coexistence because they contain advice and admonitions aimed at indicating ways for men to live and act in a cordial and respectful way. In other words, proverbs, sentences, aphorisms and maxims, among others, have great didactic-pedagogical value that are fixed in the memory and act as a code of conduct. The concise form, the simple structure and the ease of understanding of the transmitted messages allow the proverbial formulas to be memorized and transmitted with great ease among peoples and cultures. An important feature of proverbial constructs is their universality, which cannot be limited by social, ideological or geographical barriers. Its capacity for repetition and updating, which gives importance to the study of proverbs and their manifestations, is either to enrich translation studies or to signal to other researchers that there is still much to be done in this field.

Keywords: Proverbs. Culture. Oral Tradition. Translation.

\section{Introdução}

Chamamos de provérbio uma máxima ou sentença curta, de caráter prático, geralmente de origem popular, frequentemente com ritmo e rima, rica em imagens, que sintetiza um conceito, um preceito, uma norma, uma experiência, uma advertência a respeito da realidade, ou uma regra social ou moral. Quantas vezes já ouvimos alguém dizer que "a pressa é inimiga da perfeição", quando insistimos para que algo seja resolvido antes do tempo habitual ou "Deus ajuda quem cedo madruga" se desejamos alcançar um objetivo sem mostrar o menor esforço para isso. Os provérbios são ditos populares que transmitem, de geração em geração, conhecimentos comuns 
Tradição oral e tradução: a comunicação intercultural e as dificuldades para a tradução-versão dos provérbios entre o português brasileiro e o italiano

Alcebíades Arêas

Edvaldo Sampaio Belizário

Maria Aparecida Cardoso Santos

sobre as mais diversas situações que envolvem a vida e as pessoas que dela participam.

A sabedoria contida nos provérbios não deve ser, como se poderia imaginar, uma prerrogativa do povo humilde, das pessoas mais simples. O provérbio estende a sua verdade a todo ser humano e esta verdade, acreditase, é preexistente na mente humana. Neste sentido, ao dizer um provérbio, uma pessoa não ensina algo a alguém. O sentido do provérbio se impõe a quem o diz e àquele que o ouve.

Sendo assim, em função da riqueza e da complexidade que se nos apresentam no momento da tradução ou versão de provérbios para outro idioma, neste artigo, ao retomarmos definições e conceitos já há muito conhecidos, apresentamos uma proposta de tradução de provérbios para o contexto lingüístico-cultural das línguas portuguesa (BR) e italiana, com o fito de contribuir para os estudos da tradução no que se refere ao confronto específico dessas duas línguas co-irmãs.

\section{Revisitando a definição de provérbio}

Os provérbios são conhecidos, também, como:

adágio - apresenta forma e conteúdo mais popular: Pimenta nos olhos alheios é refresco; A vida é ruim, mas ninguém quer morrer,

rifão - é uma variação mais vulgar e, geralmente, contém palavras grosseiras ou chulas : Quem dizo que quer, ouve o que não quer; Ao cura e ao juiz o diabo lho diz?

anexim (do árabe na-naxíd, "canto, poema") - dito popular que expressa um conselho sábio: A esperança é a última que morre; Água mole, em pedra dura, tanto bate até que fura; 
Tradição oral e tradução: a comunicação intercultural e as dificuldades para a tradução-versão dos provérbios entre o português brasileiro e o italiano

Alcebíades Arêas

Edvaldo Sampaio Belizário

Maria Aparecida Cardoso Santos

dito ou ditado popular - frase de caráter popular: O seguro morren de velho; Apressado come cru;

aforisma (do grego aphorismos "definição") - condensa em poucas palavras um conceito filosófico, uma regra ou um conceito moral: Seria cômico, se não fosse trágico (Carlos Drummond de Andrade); A mentira é o único privilégio do homem sobre todos os outros animais (FiódorDostoiévski);

apotegma (do grego apóphyhegma "preceito") - reproduz dito ou pensamento de pessoa de autoridade: Os peronistas não são nem bons nem maus: são incorrigíveis (Jorge Luis Borges); Quem não sabe dissimular, não sabe reinar (Luís XI, rei da França); parêmia (do grego paroimía "provérbio, ditado") - provérbio ou alegoria breve: o dinheiro não socorre a quem dorme; a ocasião faz o ladrão;

axioma (do grego axios "digno,válido”) - anuncia uma evidência incontestável e válida universalmente: $A$ morte não espera; quando o barco começar a afundar, não reze, abandone-o;

sentença - proposição que traduz uma verdade moral: Quem perde a honra pelo negócio perde a honra e o negócio ; Visitantes sempre dão prazer. Senão quando chegam, pelo menos quando partem.

máxima - exprime uma regra moral, um princípio de conduta: Quem casa não pensa, quem pensa não casa; Quem não deve não teme;

princípio - estabelece norma ou regra geral: Cumpra o seu dever, suceda o que suceder, Consciência tranquila é o melhor remédio contra a insônia;

prolóquio - contém uma regra, um preceito: Em briga de marido e mulher não se mete a colher, Qem com ferro fere, com ferro será ferido.

\section{A origem dos provérbios}


Tradição oral e tradução: a comunicação intercultural e as dificuldades para a tradução-versão dos provérbios entre o português brasileiro e o italiano

Alcebíades Arêas

Edvaldo Sampaio Belizário

Maria Aparecida Cardoso Santos

A origem da palavra provérbio vem do latim proverbium, ou seja, pro “à frente, antes" mais verbum "palavra". Os provérbios aparecem pela primeira vez em textos do século XII, porém é Henri Estienne (1528-1598) quem assina, por volta de 1579, um dos mais antigos estudos sobre o assunto, cabendo ao inglês John Heywood (1497-1580) a mais antiga coleção de provérbios, com data de 1562 (XATARA, 2000, p. 13). Entretanto, é praticamente impossível determinar o momento exato do surgimento dos provérbios e da sua utilização, pois, além da sua natureza anônima, pertenciam a uma tradição oral; eram passados de geração em geração através da fala dos mais velhos e, se foram registrados de algum modo, esses documentos se perderam ao longo dos tempos. Em diversos povos da Antiguidade, os provérbios foram utilizados para incutir preceitos morais e transmitir conceitos e ideias filosóficas. Há provérbios egípcios que datam de mais de 2500 anos antes de Cristo, contudo, foram os hebreus, através das Escrituras Sagradas, os escritores gregos como Homero, Hesíodo, Sófocles, Eurípedes, Ésquilo, Platão, Aristóteles, entre outros, e os latinos, discípulos e continuadores dos gregos, entre os quais Plauto, Terêncio, Lucrécio, Cícero, Virgílio, Horácio e Sêneca que, por meio de suas obras, permitiram que eles fossem registrados e chegassem até nós (LACERDA, p. XIX, 2004). De acordo com Albuquerque,

os 'sebayts' (ensinamentos), equivalentes aos provérbios atuais, são citados desde o terceiro milênio a.C. Entre os hebreus e os aramaicos, o provérbio representava a palavra de um sábio. No século VI a.C., aparecem as Palavras de Abiqar e, no século IV a.C., os Provérbios de Salomão. Entre os gregos, 'gnômê' (pensamento) e 'paroemia' (instrução) cobrem as noções de provérbio, sentença, máxima, adágio, preceito etc., aparecendo nas obras de Platão, Aristóteles e Ésquilo. (ALBUQUERQUE, 1989, p. 35).

Podemos, então, dizer que o anonimato dá aos provérbios um caráter coletivo, e não individual, sobretudo quando pensamos nas diversas levas 
Tradição oral e tradução: a comunicação intercultural e as dificuldades para a tradução-versão dos provérbios entre o português brasileiro e o italiano

Alcebíades Arêas

Edvaldo Sampaio Belizário

Maria Aparecida Cardoso Santos

migratórias que ocorreram em todo o mundo e em diversas épocas da história da humanidade. Certamente, o contato entre os povos envolvidos nesse processo não ficou isento de influências linguísticas, dentre as quais figurou a cultura dos provérbios, tornando, com o passar dos tempos, o reconhecimento de sua origem uma tarefa quase impossível. São três as fontes geradoras de provérbios:

1) Clássica: inclui os provérbios de origem erudita: seja latina, como Não vá ao sapateiro além do chinelo (Ne sutor ultra crepidam), citado por Plínio, o Antigo, em História Naturalis, cujo significado é "não se deve ir além das suas atribuições", seja bíblica, como Dê a César o que é de César e a Deus o que é de Deus (Mateus, 22:11), através do qual Jesus adverte os seus discípulos sobre a necessidade de se cumprir as obrigações civis, pagando os impostos, seja filosófica como "O ignorante afirma, o sábio duvida, o sensato reflete", de Aristóteles;

2) Literária: inclui provérbios igualmente eruditos que provêm da literatura clássica universal, do tempo, de ditos de personalidades históricas, como $A$ razãa do mais forte é sempre a melhor (verso de La Fontaine, Fábulas) ou $O$ excesso de prudências e de cautelas conduz muitas vežes a imprudências mais perigosas (Júlio Diniz em As pupilas do Senhor Reitor);

3) Popular: são os provérbios nascidos no seio do povo, de forma e sabor característicos, que refletem, em seu conjunto, os usos e costumes, a índole e a psicologia de uma nação, e que constituem a grande massa dos adágios, rifões e anexins e se incorporam no folclore nacional. A natureza popular dos provérbios que pertencem a este tipo de fonte geradora não permite que seus autores e a data de sua aparição sejam conhecidos. Entre tantos exemplos, citamos Quem foi à roça perdeu a carroça, Quem tem pressa come cru e Quem não tem cão caşa com gato. 
Tradição oral e tradução: a comunicação intercultural e as dificuldades para a tradução-versão dos provérbios entre o português brasileiro e o italiano

Alcebíades Arêas

Edvaldo Sampaio Belizário

Maria Aparecida Cardoso Santos

\section{As características dos provérbios}

Os provérbios fazem parte da cultura e do folclore de um povo e são passados de geração em geração, diretamente, por meio da palavra. Eles passam verdades universais e coletivas e, geralmente, são utilizados pelos mais velhos que, por meio deles, transmitem autoridade, ensinam, advertem, repreendem e dão conselhos aos mais novos. Por fazerem parte da tradição oral de um povo, os provérbios transmitem conhecimento e ensinamento sobre os mais diversos assuntos que envolvem a nossa vida: saúde, trabalho, amizade, amor, inveja, ciúme, lealdade, traição, egoísmo, avareza, ganância, prudência, alegria, tristeza, morte, esperança. As pessoas usam os provérbios para dizer às outras o que fazer ou que atitude tomar em relação a uma determinada situação. Desta forma, "os provérbios são "estratégias para situações", mas estratégias com autoridade, que formulam uma parte do bom senso de uma sociedade, seus valores e a maneira de fazer as coisas". (BURKE e PORTER, 1997, p. 45).

\footnotetext{
As pessoas usam os provérbios para dizer a outras o que fazer ou que atitude tomar em relação a uma determinada situação. Assim, os provérbios são "estratégias para situações", mas estratégias com autoridade, que formulam uma parte do bom senso de uma sociedade, seus valores e a maneira de fazer as coisas. (1997, p. 45).
}

Por estarem presentes principalmente na tradição oral de um povo, os provérbios têm características específicas que facilitam a sua transmissão: são, geralmente, concisos, ritmados e rimados, para que sejam apreendidos com maior facilidade. Além disso, eles podem ter um sentido literal, metafórico, eufêmico, lúdico e irônico ao lançarem as suas mensagens moralizadoras. 
Tradição oral e tradução: a comunicação intercultural e as dificuldades para a tradução-versão dos provérbios entre o português brasileiro e o italiano

Alcebíades Arêas

Edvaldo Sampaio Belizário

Maria Aparecida Cardoso Santos

A partir do que foi exposto anteriormente, destacamos as seguintes propriedades que podem ser observadas nos provérbios:

\section{A concisão}

Os provérbios precisam ser curtos para que sejam transmitidos e apreendidos com maior facilidade: A bom entendedor, meia palavra basta; Quem desdenha quer comprar.

\section{Os recursos fonológicos}

Muitos provérbios se servem de recursos fonológicos, como ritmo, rima, aliteração e assonância, para facilitar a sua memorização e a sua transmissão entre as diversas gerações: Em briga de marido e mulher não se mete a colber; Quem não arrisca não petisca; Quem com ferro fere com ferro será ferido.

\section{Os recursos sintáticos}

As citações proverbiais são feitas com o presente indicativo para sugerir atemporalidade ou no imperativo quando contém um conselho, uma regra ou uma lei. Os provérbios se servem, também, de paralelismos, repetições e estruturas bipartidas para sua melhor assimilação: Com fogo não se brinca; Faz o que eu digo, mas não faças o que eu faço; Quem tudo quer tudo perde; Quem não tem cão caça com gato.

\section{Os recursos lexicais}

Geralmente, os provérbios são formados por palavras de cunho popular, pois, assim como outros recursos já vistos, favorecem a apreensão e a memorização por parte das pessoas:

Macaco não olha pro rabo; Pimenta nos olhos dos outros é refresco; Não conte com o ovo na barriga da galinha.

Muitas vezes, os provérbios populares sofrem variações com a inserção de palavras chulas no lugar de outras menos vulgares. O artifício é, em alguns 
Tradição oral e tradução: a comunicação intercultural e as dificuldades para a tradução-versão dos provérbios entre o português brasileiro e o italiano

Alcebíades Arêas

Edvaldo Sampaio Belizário

Maria Aparecida Cardoso Santos

casos, utilizado para dar ao provérbio uma característica mais ofensiva e impactante:

Pimenta no cu dos outros é refresco; Não conte com o ovo no cu da galinha.

Há, também, por outro lado, o uso de provérbios que são arcaicos no seu vocabulário ou construção. $\mathrm{O}$ uso do arcaísmo, no entanto, não tira do provérbio o seu caráter coloquial, mas, reforça, por sua vez, sua característica de autoridade própria da sabedoria universal. Nos dois exemplos seguintes, mostramos os provérbios na sua forma arcaica e os seus correspondentes mais modernos: A cobiça rompe o saco/ Quem tudo quer tudo perde; Na arca aberta o justo peca/ A ocasião fazo o ladrão.

\section{A mensagem universal}

Os provérbios são sentenças de caráter universal que contêm conselhos sábios e ensinam princípios de conduta que se aplicam às mais variadas culturas espalhadas pelo mundo. Muitos provérbios são traduzidos para diversas línguas, ampliando, assim, a sua universalidade e a sua aplicabilidade em diferentes culturas. O provérbio de origem latina Quitacet, consentire videtur, difundido por Bonifácio VIII, papa entre 1294 e 1303, tem uma versão em várias línguas: Quem cala, consente (português), Chi tace acconsente (italiano), Qui encalla ortoga (espanhol), Silence gives consent (inglês), Qui ne dit mot consent (francês), Cine tace, aproba (romeno), Wer schweigt, stimmt zu (alemão).

Podemos encontrar, contudo, com menor frequência, provérbios que não possuem equivalentes em outra língua por refletirem tipicamente a cor local de uma determinada cultura. Claudia Maria Xatara e Thais Marini Succi, no seu artigo Revisitando o conceito de provérbio ${ }^{4}$, afirmam que o ditado popular Quem não gosta de samba é ruim da cabeça ou doente do pé é um tipo de sentença que

\footnotetext{
${ }^{4}$ XATARA, Claudia Maria e SUCCI, Thais Marini. Revisitando o conceito de provérbio, p. 38. Disponível em: http://www.ufff.br/revistaveredas/file/2009/12/artigo31.pdf. Acesso em 12 out 2018.
} 
Tradição oral e tradução: a comunicação intercultural e as dificuldades para a tradução-versão dos provérbios entre o português brasileiro e o italiano

Alcebíades Arêas

Edvaldo Sampaio Belizário

Maria Aparecida Cardoso Santos

não pode experienciar outra cultura senão a brasileira, confirmando, assim, a especificidade cultural que determinados provérbios têm em relação ao local de sua difusão.

\section{O valor moralizante e didático}

Os provérbios sempre se remetem à educação moral, e quem os usa pretende passar ao seu interlocutor uma autoridade pela posse da sabedoria universal. Embora os provérbios sejam um patrimônio da coletividade, quando são usados, refletem a intenção moralizadora e didática de quem os cita e servem para solucionar problemas cotidianos que colocam em conflito a harmonia coletiva. Por este motivo, os provérbios têm o poder de ensinar, aconselhar, incentivar, advertir, intimidar, fazer refletir, repreender, consolar e

orientar: Quem com porcos se mistura, farelos come (contém uma advertência); $A$ pressa é inimiga da perfeição (contém uma orientação); Depois da tormenta, sempre vem a bonança (contém uma consolação); De grão em grão a galinha enche o papo (contém um ensinamento); Aqui se faz̧ aqui se paga (contém uma intimidação); Agua mole em pedra dura, tanto bate até que fura (contém um incentivo); Faz o que eu digo, mas não faças o que eu faço (contém um conselho); Há males que vêm para o bem (contém uma reflexão; Quem dizo o que quer, ouve o que não quer (contém uma repreensão).

\section{$\mathrm{O}$ alto poder comunicativo}

Por serem concisos, fáceis de se memorizar, e por transmitirem conhecimentos comuns sobre os diversos aspectos da vida cotidiana, os provérbios têm um grande poder comunicativo. Quem usa um provérbio comunica com rapidez e clareza. A longa explicação, que vem implícita no provérbio, não é necessária, uma vez que é de comum conhecimento dos membros de uma sociedade. Portanto, se quisermos dizer a alguém que a prudência nos manda ficar com aquilo que já temos garantido e não 
Tradição oral e tradução: a comunicação intercultural e as dificuldades para a tradução-versão dos provérbios entre o português brasileiro e o italiano

Alcebíades Arêas

Edvaldo Sampaio Belizário

Maria Aparecida Cardoso Santos

pensarmos na possibilidade de termos mais, com o risco de perdermos tudo, é muito mais fácil e ágil usarmos o provérbio: Mais vale um pássaro na mão do que dois voando, uma vez que a sua capacidade de comunicar é mais eficiente e produtiva. E se quiséssemos, ainda, aconselhar alguém através de uma posição oposta àquela da prudência, a extensa explanação poderia ser substituída pelo breve provérbio: Quem não arrisca, não petisca.

\section{A riqueza do conteúdo semântico}

Pelo seu forte conteúdo semântico, os provérbios falam dos mais variados assuntos que envolvem a vida: saúde, trabalho, amizade, amor, inveja, ciúme, lealdade, traição, egoísmo, avareza, ganância, prudência, alegria, tristeza, morte, esperança. Expressam opiniões gerais, mais do que pessoais, que são endossadas por toda a sociedade, pois não pertencem a este ou àquele membro, mas a todos: Saúde cuidada, vida conservada (saúde); Deus ajuda quem cedo madruga (trabalho); No aperto do perigo, conhece-se o amigo (amizade); Amor com amor se paga (amor); A inveja é o suplício das almas vis (inveja); O ciume nascen cego e morreu surdo (ciúme); A franqueza pode ser reprovada, a lealdade é sempre apreciada (lealdade); Ainda que a traição agrade, o traidor sempre aborrece (traição); A ingratidão é a mão esquerda do egoísmo (egoísmo); A avareza é a chave da pobrez̧a (avareza); Quem tudo quer, tudo perde (ganância); O seguro morren de velho (prudência); As grandes alegrias merecem partilha (alegria); Tristeza sem alegria, dobrada fadiga (tristeza); A morte espreita mas não espera (morte); Enquanto bá vida, bá esperança (esperança).

\section{A constituição literal}

Os provérbios têm uma composição literal quando as palavras que os formam não precisam de uma interpretação metafórica para a compreensão da mensagem, da advertência, do conselho nelas inseridos. Poucos provérbios têm esta característica e, mesmo nestes casos, podemos encontrar-lhes, 
Tradição oral e tradução: a comunicação intercultural e as dificuldades para a tradução-versão dos provérbios entre o português brasileiro e o italiano

Alcebíades Arêas

Edvaldo Sampaio Belizário

Maria Aparecida Cardoso Santos

quando convenha, um sentido metafórico: Não faças aos outros o que não queres que te façam a ti, Uma desgraça nunca vem só.

\section{A constituição metafórica}

Identifica-se a constituição metafórica quando as imagens expressas no provérbio nos remetem a uma interpretação que vai além do sentido literal das palavras que o compõem. A maioria dos provérbios comunica através da linguagem conotativa, ou seja, o provérbio deve ser entendido a partir daquilo que a mensagem sugere: Quem com porcos se mistura, farelos come (Quem vive com pessoas de má índole, acaba se tornando como elas); De grão em grão a galinha enche o papo (Aos poucos se pode alcançar um objetivo); Um dia da caça, o outro do caçador (Um dia temos sorte, outro dia não); Uma andorinha só não faz verão. (Para as grandes mudanças é preciso a participação de várias pessoas); Á noite todos os gatos são pardos (Todas as coisas têm a mesma aparência no escuro).

\section{O aspecto lúdico-humorístico}

O humor e a criatividade também estão presentes na cultura proverbial, sobretudo quando falamos dos famosos antiprovérbios, que são variações dos provérbios tradicionais. Quem não tem cão, caça com cachorro, diria um gaiato qualquer para deixar o provérbio engraçado. A utilização deste aspecto lúdicohumorístico dos provérbios pode ser observada no título da peça Quem ri por último é loira ou português, do humorista Jorge Paulo, que é uma variação bemhumorada do famoso provérbio Quem ri por último ri melhor. Outros exemplos são: Depois da meia-noite urubu vira frango; Quem ri por último tem raciocinio lento; Depois da tempestade vem a gripe.

\section{O caráter irônico}

Em comunhão com o aspecto lúdico-humorístico dos provérbios está a característica irônica que muitos provérbios possuem. Geralmente, os provérbios com teor irônico têm uma origem anônima, pois são frutos de um 
Tradição oral e tradução: a comunicação intercultural e as dificuldades para a tradução-versão dos provérbios entre o português brasileiro e o italiano

Alcebíades Arêas

Edvaldo Sampaio Belizário

Maria Aparecida Cardoso Santos

olhar crítico que tenta, de algum modo, desconstruir os ensinamentos oriundos das experiências coletivas transmitidas ao longo das gerações, substituindo-os por novos conceitos que se opõem ao tradicional pensamento coletivo. No conjunto da obra do escritor mineiro Guimarães Rosa, encontramos inúmeros exemplos de provérbios com teor irônico. Para citar um exemplo, lembramos aqui o aforismo Viver é negócio muito perigoso, que é citado algumas vezes no seu livro Grande Sertão: Veredas. O provérbio do escritor mineiro é uma clara ironia que se contrapõe a provérbios como $A$ vida é bela; Viver é muito bom, é uma dádiva, Viver é recordar. Outros exemplos são: Se caminhar fosse bom para a saúde, carteiro não ficaria doente; Virgindade é coisa que dá e passal; A verdadeira felicidade está nas pequenas coisas: um pequeno iate, um pequeno Rolex, uma pequena mansão, uma pequena fortuna; Se tudo que é bom dura pouco, eu já deveria ter morrido há muito tempo; Otimistas são pessimistas mal informados; Quem acha tudo gozado é camareira de motel; Viva cada dia como se fosse o último; Um dia você acerta. (Luís Fernando Veríssimo).

\section{A função eufemística}

Como já vimos, os provérbios têm um valor moralizante e didático e, por isso, são utilizados muitas vezes para se lançar uma advertência. Contudo, reforçada principalmente pelo caráter metafórico dos provérbios, a admoestação funciona como uma forma eufêmica de se dizer algo desagradável. O provérbio Quem diz o que quer, ouve o que não quer, por exemplo, serve para evitar uma advertência mais direta e contundente como Se você falar mal de alguém, vai ouvir coisas piores, tornando a repreensão mais suave e menos impactante.

\section{Os antiprovérbios}

Os antiprovérbios são corruptelas dos provérbios tradicionais que, de uma forma lúdica e sarcástica, corrompem o significado original das 
Tradição oral e tradução: a comunicação intercultural e as dificuldades para a tradução-versão dos provérbios entre o português brasileiro e o italiano

Alcebíades Arêas

Edvaldo Sampaio Belizário

Maria Aparecida Cardoso Santos

mensagens moralizantes que eles denotam. Para que um antiprovérbio seja criado, é muito importante que se conheça o significado do provérbio para, assim, inverter-se o seu sentido e se criar outro. Quando alguém cria o antiprovérbio, desvirtua da sentença original o sentido moralizador, dando-lhe uma significação novo e espirituoso. Alguns exemplos de antiprovérbios são: Quem ri por último é retardado por Quem ri por último, ri melhor; Gato escaldado morre por Gato escaldado tem medo de água fria; Depois da tempestade vem a gripe por Depois da tempestade vem a bonança; Águas passadas já passaram por Águas passadas não movem moinhos; Quem cedo madruga fica com sono o dia inteiro por Deus ajuda quem cedo madruga; Quem espera tem que aguardar por Quem espera sempre alcança; Devagar não se vai a lugar nenhum por Devagar se vai longe; Quem não tem cão, caça com cachorro por Quem não tem cão, caça com gato; Antes só do que mal acompanhado por Antes mal acompanbado do que só.

\section{Alguns ditos populares e suas devidas correções}

Alguns ditos populares, ao passarem de geração a geração, perdem o seu significado primário, que é renovado pela tradição oral. Esses ditos têm origens remotas e, muitas vezes, o seu sentido original é ignorado pelas pessoas que se utilizam deles. Não é tarefa fácil apontar as causas dessas alterações e a partir de quando foram acontecendo, mas podemos dizer que parte dessas modificações se deu pela proximidade sonora das palavras ou pela interpretação equivocada do significado original delas. Alguns exemplos de ditos populares, que tiveram sua origem com significado diferente do que aplicamos hoje, são: dito popular: Quem tem boca vai a Roma (dito original: Quem tem boca vaia Roma); dito popular: Cuspido e escarrado [que é muito semelhante] (dito original: Esculpido em carraro [tipo de mármore]); dito popular: Ele não para quieto, parece que tem bicho carpinteiro (dito original: Ele não para quieto, parece que 
Tradição oral e tradução: a comunicação intercultural e as dificuldades para a tradução-versão dos provérbios entre o português brasileiro e o italiano

Alcebíades Arêas

Edvaldo Sampaio Belizário

Maria Aparecida Cardoso Santos

tem bicho no corpo inteiro); dito popular: Quem não tem cão, caça com gato (dito original: Quem não tem cão, caça como gato[sozinho e com astúcia]); dito popular: Batatinha quando nasce, esparrama pelo chão (dito original: Batatinha quando nasce, espalha a rama pelo chão); dito popular: Cor de burro quando foge (dito original: Corra do burro, quando ele foge ( porque o burro enfurecido é muito perigoso).

\section{Uma proposta para a tradução de provérbios a partir das línguas italiana e portuguesa do Brasil}

Quem se propõe a traduzir, geralmente, se pergunta se deve fazer uma tradução literal, palavra por palavra, ou uma tradução livre. Na verdade, não há tradução literal ou livre. A tradução deve sempre levar em consideração as características linguísticas tanto da "língua de partida" quanto da "língua de chegada", para se evitar qualquer tipo de adulteração da mensagem (RÓNAI, 1981, p. 18).

$\mathrm{Na}$ frase "Gli azzurri hanno vinto quattro campionati mondiali di calcio", a palavra "azzurn" tem uma conotação própria da cultura italiana, quando faz uma clara referência a toda equipe, isto é, aos jogadores que pertencem à seleção nacional de um determinado esporte. $\mathrm{Na}$ frase acima, a referência ao futebol vem citada na própria frase (quattro campionati di calcio). Os “azそurn” são os jogadores que defendem as cores da sua equipe; no caso da italiana, a cor predominante é a azul. ${ }^{5} \mathrm{~A}$ mesma força expressiva não tem a palavra "aqzurro"

\footnotetext{
${ }^{5}$ Há diferentes hipóteses sobre a escolha da cor azul (colore azzurro): uma delas, é que a cor azul tivesse sido copiada da camisa francesa; outra, é que o azul representasse a cor do céu e dos mares italianos; uma nova hipótese tem sua origem do seguinte fato: na sua estreia, em 1910, a equipe italiana de futebol usava a cor branca em homenagem ao clube Pro Vercelli, time de futebol mais forte da Itália no momento, embora, algumas fontes históricas digam que o branco foi usado, inicialmente, porque não se havia chegado a um acordo sobre a cor do uniforme e, assim, foi decidido que uma cor neutra fosse usada. Entretanto, a cor branca foi substituída pela azul quando a seleção italiana foi disputar uma partida contra a seleção da Hungria, em 6 de janeiro de 1911, em Milão, num dia de forte nevada e, para não atrapalhar os jogadores italianos, foi decidida a mudança da cor da camisa. $\mathrm{Na}$ verdade, as fontes históricas explicam que a cor azul foi escolhida porque
} 
Tradição oral e tradução: a comunicação intercultural e as dificuldades para a tradução-versão dos provérbios entre o português brasileiro e o italiano

Alcebíades Arêas

Edvaldo Sampaio Belizário

Maria Aparecida Cardoso Santos

ao definir as cores dos olhos de uma pessoa, pois a cor não substitui "os olhos" e precisa sempre vir acompanhada da palavra que ela qualifica. Assim, não caberia em italiano a construção "Gli az̧urri di Anna sono affascinanti”.

A expressão italiana "zucchero filato", é constituída pelas palavras "açúcar" e "em fios", que em português corresponde ao termo "algodão-doce". Como podemos notar, a tradução do termo em português não tem nenhuma ligação literal com as palavras que formam a expressão italiana. Uma faz referência ao material e ao modo como se faz a guloseima (zuccherofilato), a outra (algodãodoce), por sua vez, refere-se à sua aparência e ao seu gosto. Portanto, "é difícil elaborar um código ou um manual de tradução. As aplicações possíveis de qualquer palavra são inúmeras e imprevisíveis" (RÓNAI, 1981, p. 18). O tradutor deve estar sempre alerta para proporcionar soluções para as mais diversas situações, apoiando-se, sobretudo, num sólido conhecimento cultural de ambas as línguas com as quais faz o seu trabalho.

Duas línguas se diferenciam, também, no aspecto formal. Não é raro haver na lingua de partida palavras que não existem na lingua de chegada ou haver uma palavra para duas significações distintas. A palavra italiana "nipote" serva para determinar, em português, tanto "neto" quanto "sobrinbo". Em português, há uma nítida distinção entre os verbos "levar" e "traz̧er" que, em italiano, não parece tão clara, pois usamos para as duas situações um único verbo: "portare". Assim, temos: A) Che cosa mi hai portato da Roma?/ O que você me trouxe de Roma?; B) Porto i bambini a scuola/Levo as criancas para a escola.

A palavra italiana "cacciavite" (chave de fenda) carrega consigo uma riqueza expressiva na sua formação por causa da presença do verbo "cacciare", que

representava as cores da Casa de Saboia, dinastia que reinava na Itália à época. Os Saboia, por sua vez, tinham escolhido tal cor por causa do manto, tradicionalmente azul, da Virgem Maria, da qual eram devotos. (CHIESA, Carlo Felice \& BERTOZZI, Lamberto. Il secolo azzurro: 1910-2010. Bologna: Minerva Edizioni, 2011, p. 15-17) 
Tradição oral e tradução: a comunicação intercultural e as dificuldades para a tradução-versão dos provérbios entre o português brasileiro e o italiano

Alcebíades Arêas

Edvaldo Sampaio Belizário

Maria Aparecida Cardoso Santos

pode significar tanto "introduzir " quanto "retirar", funções específicas de uma chave de fenda. Desta forma, temos a seguinte formação: "caccia" = introdur, retira e "vite" = parafuso.

Quando se trabalha com tradução, devem-se considerar as questões de caráter estilístico que estão ligadas intimamente com a produção do discurso: a escolha da palavra (Andare dal benzinaio [frentista]/Ir ao posto de gasolina); a posição da palavra no discurso (Sono già le nove/ Já são nove horas; Carla è una mia amica/Carla é uma amiga minha); a combinação das palavras (Io mi mangio una mela/Eu como uma maça ); a forma verbal (Divento professore/ Torno-me professor, L'autobus si ferma/O ônibus para); a regência verbal (Conto sui miei genitori/Conto com meus pais; Vado a bere um biccbiere d'acqua/Vou beber um copo de água/Mi piace parlare italiano/Gosto de falar italiano), etc. Aqui, parece-nos interessante a fórmula: "traduzir o mais literalmente possível, mas com toda a liberdade que for possível".

Cada palavra a ser traduzida está intimamente ligada ao contexto geral do texto. A tradução de uma palavra isolada do contexto no qual está inserida é uma pretensiosa ilusão. Para uma segura tradução, a palavra deve estar inserida numa frase, a frase no parágrafo e o parágrafo em todo o texto. $\mathrm{O}$ eterno dilema do tradutor é: "digo aquilo que o autor disse, ou digo o que ele pretende expressar?" No primeiro caso, a tradução é mais ou menos literal e o leitor deve interpretar o seu sentido, enquanto no segundo caso, a interpretação é feita pelo tradutor e o leitor recebe um trabalho mais compreensível, mas menos fiel ao original. No primeiro caso, há ainda o risco de se perder o conceito que o autor queria expressar, no segundo, há o risco de se apresentar o ponto de vista do tradutor e não o do autor.

No caso particular de provérbios, devemos lembrar que, por sintetizarem um conceito a respeito da realidade ou uma regra social e moral, 
Tradição oral e tradução: a comunicação intercultural e as dificuldades para a tradução-versão dos provérbios entre o português brasileiro e o italiano

Alcebíades Arêas

Edvaldo Sampaio Belizário

Maria Aparecida Cardoso Santos

os provérbios devem ter uma tradução que transcenda os limites do léxico, deixando de ser uma tradução literal para transformar-se naquilo que poderíamos chamar de "tradução cultural".

Uma vez que expressam a sabedoria e a cultura de um povo, os provérbios não devem ser traduzidos literalmente, uma vez que tal medida representa um risco para a essência da sua significação. Na verdade, no momento de se traduzir um provérbio, deve-se encontrar um equivalente na outra língua, independentemente da aproximação ou não do léxico, observando-se, sobretudo, se o aspecto moralizador é o mesmo. Portanto, o que se traduz não é o conjunto das palavras que formam o provérbio, mas o seu sentido moralizante, tendo ele, ou não, semelhança lexical com o equivalente na outra língua. Tomando como parâmetro a língua portuguesa do Brasil e a língua italiana, encontramos no universo da paremiologia uma variedade de situações em que podemos verificar uma dessemelhança ou uma semelhança total ou parcial na constituição lexical dos provérbios.

No provérbio: Um dia da caşa, outro do caçador, não há nenhuma semelhança lexical com o equivalente em língua italiana: Una volta corre il cane e un'altra La lepre (tradução literal: Uma vez corre o cão e outra a lebre); entretanto, o sentido moralizador é o mesmo, ou seja, num dia você tem sorte ou vence, noutro você tem azar ou perde. Já no provérbio Em briga de marido e mulher não se mete a colher, podemos obervar uma semelhança parcial em relação ao equivalente em italiano Tra moglie e marito non mettere il dito, no qual acontece a mudança da ordem das palavras "marido" e "mulher" (moglie e marito) no início do provérbio e, no final, o uso de substantivos diferentes "colher" e "dito" (dedo), em função da necessidade rimática. Contudo, a mensagem moralizadora é a mesma, isto é, não devemos nos envolver em briga de casal. Há, também, provérbios que possuem uma total semelhança lexical em 
Tradição oral e tradução: a comunicação intercultural e as dificuldades para a tradução-versão dos provérbios entre o português brasileiro e o italiano

Alcebíades Arêas

Edvaldo Sampaio Belizário

Maria Aparecida Cardoso Santos

comparação com o seu correspondente na outra língua, e, no caso particular do português (BR) e do italiano, a semelhança se dá, principalmente, por se tratar da mesma origem que ambas as línguas têm, ou seja, o latim, de cuja cultura linguística provém a grande maioria dos provérbios. É o caso do provérbio Cão que ladra não morde, que em língua italiana é Can Che abbaia non morde. Neste exemplo, podemos verificar uma analogia na escolha das palavras e o sentido moral é o mesmo, ou seja, quem faz muitas ameaças, geralmente não vai às vias de fato.

No momento de se traduzir um provérbio, nunca se pode desvirtuar o seu sentido moralizador em função de um rigor de caráter lexical. Às vezes, uma combinação de palavras de uma língua não cria um efeito ou uma mensagem moral que possa ser compreendida em outro meio cultural. Por este motivo, o tradutor que se depara com um provérbio deve procurar na outra língua um de igual valor para utilizá-lo no texto que irá traduzir. Mesmo nos casos em que não há equivalência nas duas línguas, o tradutor deve ser muito criterioso no momento de traduzir um provérbio, fazendo uma pesquisa minuciosa sobre a aplicabilidade das palavras dentro do contexto cultural de cada língua, para que o efeito moralizador nunca perca a sua essência.

São inúmeros os provérbios em língua portuguesa (BR) que têm um correspondente em língua italiana, seja pela sua dessemelhança, pela sua semelhança parcial ou total. Eis alguns deles: $A$ casa de tua tia, não vás todo dia / Ospite raro ospite caro; A fome é má conselheira / La fame è cattiva consigliera; À noite todos os gatos são pardos / Al buio tutti i gatti sono bigi; A união faz a força / L'unione fa La forza; Água mole em pedra dura, tanto bate até que fura / A goccia a goccia si scava la pietra; A mentira tem pernas curtas / Le bugie banno le gambe corte; Antes tarde do que nunca / Meglio tardi che m; Cada um por si e Deus por todos / Ognuno per sé e Dio 
Tradição oral e tradução: a comunicação intercultural e as dificuldades para a tradução-versão dos provérbios entre o português brasileiro e o italiano

Alcebíades Arêas

Edvaldo Sampaio Belizário

Maria Aparecida Cardoso Santos

per tutti; Com fogo não se brinca / Col fuoco non si scherza; De grão em grão a galinha enche o papo (também Devagar se vai longe) / Chi va piano va sano e va lontano; Dizei-me com quem andas e eu te direi quem és / Chi va com lo zoppo, impara a zoppicare; É melhor prevenir do que remediar / Prevenire è meglio che curare; Em boca fechada não entra mosca / In bocca chiusa non entrano mosche; Em casa de ferreiro, espeto de pau / In casa Del fabbro spiedo di legno; Enquanto há vida, há esperança / Finche c'è vita, c'è speranza; Falar é fácil, fazerer que é dificil / Tra il dire e il fare c'è in mezzo il maré; Faz o que en digo, mas não faças o que en faço / Fa quel Che il prete dice, non quel Che il prete fa; Gosto não se discute / Tutti i gusti son gusti; Mais vale um pássaro na mão do que cem voando / Meglio l'uovo oggi Che la gallina domani; Nada como um dia após o outro / La notte porta consiglio; Não conte com o ovo na barriga da galinha / Non vendere La pelle dell'orso prima di averlo ucciso; Onde bá fumaça, há fogo / Non c’è fumo senza arrosto; Os últimos serão os primeiros / Gli ultimi saranno i primi; Panela velha é que faz comida boa / Gallina vecchia fa buon brodo; Quando o gato sai, os ratos fazem a festa / Quando il gatto non c'è i topi ballano; Quem avisa, amigo é / Uomo avvisato mezzo salvato; Quem cala, consente / Chi tace acconsente; Quem não arrisca, não petisca / Chi non risica non rosica; Quem tudo quer, tudo perde / Chi troppo vnole nulla stringe; Toda regra tem exceção / Non c'è regola senz̧a eccezioni; Uma desgraça nunca vem só / Le disgrazie non vengono mai sole; Uma andorinha só não faz. verão / Una rondine non fa primavera.

\section{Considerações finais}

Do quanto foi visto no presente artigo, acreditamos que fica clara a importância da presença dos provérbios, das máximas, das sentenças e dos aforismos - dentre outas formas apresentadas - na formação cultural das pessoas, especialmente naquilo que concerne à manutenção da memória social dos povos e da valorização da tradição oral. Além disso, são fundamentais na consolidação de valores morais e princípios de convivência social por 
Tradição oral e tradução: a comunicação intercultural e as dificuldades para a tradução-versão dos provérbios entre o português brasileiro e o italiano

Alcebíades Arêas

Edvaldo Sampaio Belizário

Maria Aparecida Cardoso Santos

conterem, mesmo que de maneira por vezes implícita, conselhos que indicam modos de bem viver, de viver em harmonia, de não extrapolar os limites e as limitações das pessoas com as quais convivemos. Em outras palavras, os provérbios e todas as formas que lhe seguem têm importante e indiscutível valor didático-pedagógico que se fixa na memória e acaba atuando como um código de conduta.

A forma concisa e o uso de palavras simples com estrutura lógica de fácil compreensão permitem que as fórmulas proverbiais sejam memorizadas e transmitidas com grande facilidade independentemente do uso que se faça delas, posto que nem sempre é simples evitar que as pessoas tentem tirar o cisco dos olhos alheios sem cuidar das suas próprias traves oculares.

Importante é destacar, mesmo correndo o risco de sermos repetitivos, que uma característica mais importante das construções proverbiais é o seu caráter de universalidade. Com efeito, essas formas não encontram limites nem conhecem barreiras sociais, ideológicas ou geográficas. Ao contrário, estão presentes em todos os países e em todas as culturas do mundo cujos povos, independentemente de classe social ou de filiação político-ideológica, têm a grande responsabilidade de mantê-los vivos por meio de repetições e de atualizações.

E é exatamente essa capacidade de repetição e atualização que confere importância ao estudo dos provérbios e de suas manifestações. No presente artigo, em que apresentamos uma parte de um projeto muito mais extenso, defendemos uma proposta para a tradução de provérbios ao fazer a análise contrastiva entre os provérbios produzidos em língua portuguesa do Brasil e aqueles produzidos em língua italiana, visando não apenas ao enriquecimento dos estudos da tradução, mas, também, à sinalização a outros pesquisadores de que ainda existe muito a ser feito nesse campo. 
Tradição oral e tradução: a comunicação intercultural e as dificuldades para a tradução-versão dos provérbios entre o português brasileiro e o italiano

Alcebíades Arêas

Edvaldo Sampaio Belizário

Maria Aparecida Cardoso Santos

\section{Referências bibliográficas}

ALBUQUERQUE, Maria Helena Trench de. Um exame pragmático do uso de enunciados proverbiais nas interpretações verbais correntes. São Paulo: Universidade de São Paulo, 1989. BURKE, Peter e PORTER, Roy. História social da linguagem. Trad. Alvaro Hattnher. São Paulo: Fundação Editora da UNESP, 1997.

CHIESA, Carlo Felice \& BERTOZZI, Lamberto. Il secolo azzurro: 1910-2010. Bologna: Minerva Edizioni, 2011.

LACERDA, Roberto Cortes de, LACERDA, Helena da Rosa Cortes de e ABREU, Estela dos Santos. Dicionário de provérbios: francês, português, inglês. $2^{\text {a }}$ ed. São Paulo: Editora UNESP, 2004.

RÓNAI, Paulo. A traducão vivida. $2^{\text {a }}$ ed. Rio de Janeiro: Nova Fronteira, 1981. XATARA, Cláudia Maria e OLIVEIRA, Wanda Leonardo de. Dicionário de provérbios, idiomatismos e palavrões: francês-português/português-francês. São Paulo: Cultura, 2002.

XATARA, Claudia Maria e SUCCI, Thais Marini. Revisitando o conceito de provérbio. Disponível em: http://www.ufff.br/revistaveredas/file/2009/12/artigo31. pdf. Acesso em 12 out 2016. 


\title{
Tradizione orale e traduzione: la comunicazione interculturale e le difficoltà nella traduzione-versione dei proverbi tra il portoghese brasiliano e l'italiano $^{6}$
}

\author{
Alcebiades Arêas ${ }^{7}$ \\ Edvaldo Sampaio Belizário 8 \\ Maria Aparecida Cardoso Santos ${ }^{9}$
}

RIASSUNTO: I proverbi fanno parte della cultura e del folclore di un popolo e vengono trasmessi di generazione in generazione, direttamente, attraverso la parola. I proverbi trasmettono la conoscenza e l'insegnamento degli aspetti più diversi della vita, poiché fanno parte della tradizione orale di un popolo. Inoltre, sono fondamentali nel consolidamento dei valori morali e dei principi di convivenza sociale perché contengono consigli e ammonimenti che mirano a indicare modi in cui gli uomini possano vivere e agire in modo cordiale e rispettoso. In altre parole, proverbi, frasi, aforismi e massime, tra gli altri, hanno un grande valore didattico-pedagogico che si fissa nella memoria e agisce come un codice di condotta. La forma concisa, la struttura semplice e la facilità di comprensione dei messaggi trasmessi consentono di memorizzare e trasmettere le formule proverbiali con grande facilità tra i popoli e le culture. Una caratteristica importante dei costrutti proverbiali è la loro universalità, che non può essere limitata da barriere sociali, ideologiche o geografiche. La capacità di ripetizione e aggiornamento dei proverbi conferisce importanza al loro studio, sia per arricchire la ricerca nel campo della traduzione, sia per segnalare ad altri ricercatori che c'è ancora molto da fare. In questo articolo oltre a ricuperare il concetto di proverbio, la sua origine, le sue variazioni e cambiaenti semantici attraverso il tempo e lo spazio, presentiamo una proposta per tradurre proverbi nel contesto linguistico culturale delle lingue portoghese, variante brasiliana, e italiana.

Parole-chiave: Proverbi. Cultura. Tradizione orale. Proposta di traduzione

ABSTRACT: Proverbs are part of the culture and folklore of a people and are passed on from generation to generation, directly, through the word.

-Versione di Alcebiades Arêas e Edvaldo Sampaio Belizário

7Dottore in Lettere Neolatine presso la UFRJ. Docente di Lingua, Letteratura e Cultura italiane presso la UERJ.

${ }^{8}$ Master in Letteratura italiana presso la USP. Docente di Lingua, Letteratura e Cultura italiane presso la UERJ.

${ }^{9}$ Dottoressa in Lingua Portoghese presso la UERJ. Docente di Lingua e Cultura italiane presso la UERJ. 
Tradição oral e tradução: a comunicação intercultural e as dificuldades para a tradução-versão dos provérbios entre o português brasileiro e o italiano

Alcebíades Arêas

Edvaldo Sampaio Belizário

Maria Aparecida Cardoso Santos

Proverbs transmit knowledge and teaching about the most diverse aspects of life, as they are part of a people's oral tradition. In addition, they are fundamental in the consolidation of moral values and principles of social coexistence because they contain advice and admonitions aimed at indicating ways for men to live and act in a cordial and respectful way. In other words, proverbs, sentences, aphorisms and maxims, among others, have great didactic-pedagogical value that are fixed in the memory and act as a code of conduct. The concise form, the simple structure and the ease of understanding of the transmitted messages allow the proverbial formulas to be memorized and transmitted with great ease among peoples and cultures. An important feature of proverbial constructs is their universality, which cannot be limited by social, ideological or geographical barriers. Its capacity for repetition and updating, which gives importance to the study of proverbs and their manifestations, is either to enrich translation studies or to signal to other researchers that there is still much to be done in this field.

Keywords: Proverbs. Culture. Oral Tradition. Translation.

\section{Introduzione}

Definiamo un proverbio come una massima o una sentenza breve, di carattere pratico, generalmente di origine popolare, spesso con ritmo e rima, ricca in immagini, sintetizzando un concetto, un precetto, una norma, un'esperienza, un'avvertenza riguardo la realtà, o una regola sociale o morale. Quante volte abbiamo sentito dire che "chi va piano va sano e va lontano", quando insistiamo perché qualcosa avvenga fuori dal suo tempo abituale. "Chi dorme non piglia pesce", sentirá quello che desidera vincere senza sforzo, senza lavorare. I proverbi sono detti popolari che trasmettono d'una generazione all'altra le conoscenze condivise sulle più diverse situazioni che coinvolgono la vita e le persone che ci partecipano.

La saggezza che c'è nei proverbi non è, come si potrebbe immaginare, una prerogativa del popolo umile, delle persone modeste. Il proverbio estende la sua verità a tutti gli uomini e questa verità preesiste nella mente 
Tradição oral e tradução: a comunicação intercultural e as dificuldades para a tradução-versão dos provérbios entre o português brasileiro e o italiano

Alcebíades Arêas

Edvaldo Sampaio Belizário

Maria Aparecida Cardoso Santos

umana. In questo senso, quando usiamo il proverbio, non insegniamo nulla a nessuno. Il proverbio di per sé insegna a chi lo usa e a chi lo ascolta.Quindi, considerate la sua ricchezza e la sua complessità affrontate nel momento della traduzione o versione dei proverbi in un'altra lingua, in questo articolo, oltre a rivisitare le definizioni e i concetti da molto conosciuti, presentiamo una proposta di traduzione per i proverbi nel contesto culturale delle lingue portoghese brasiliana e italiana, con lo scopo di contribuire per gli studi della traduzione nel confronto specifico di queste due lingue sorelle.

\section{Rivisitando la definizione di proverbio}

I proverbi vengono conosciuti anche come:

Adagio $\rightarrow$ possiede forma e contenuto più popolare. Esempio: Can che abbaia non morde; chi va piano, va sano e va lontano.

Motto $\rightarrow$ è più volgare e, solitamente, contiene parole grossolane o di basso livello. Esempi: Chi dice quel che non vuole, sente quel che non vorrebbe.

Sentenza popolare $\rightarrow$ (dall'arabo na-naxíd, "canto, poema") detto popolare che esprime un consiglio sapiente. Esempi: La speranza non muore mai; Fai del bene e scordatelo, fai del male e pensaci.

Detto popolare $\rightarrow$ sentenza di carattere popolare. Esempio: Chi troppo vuole, nulla stringe; Chi tace acconsente.

Aforismo $\rightarrow$ (dal greco aphorismos "definizione") condensa in poche parole un concetto filosofico, una regola o un concetto morale. Esempi:Saggez?a compassione e coraggio sono le tre qualita' morali universalmente riconosciute.

Apotegma $\rightarrow$ (dal greco apóphyhegma "precetto") riproduce un detto o un pensiero di una autorità. Esempi: La vita è troppo povera per non essere anche immortale. (Jorge Luis Borges).

Paremia $\rightarrow$ (dal greco paroimía " proverbio, ditado") proverbio o allegoria breve. Esempi: L'abito non fa il monaco; L'occasione fa l'uomo ladro. 
Tradição oral e tradução: a comunicação intercultural e as dificuldades para a tradução-versão dos provérbios entre o português brasileiro e o italiano

Alcebíades Arêas

Edvaldo Sampaio Belizário

Maria Aparecida Cardoso Santos

Assioma $\rightarrow$ (dal greco axios "degno, valido" annuncia un'evidenza incontestabile e valida universalmente. Esempi: C'è un limite oltre il quale la sopportazione cessa di essere una virtù.

Sentenza $\rightarrow$ proposizione che traduce una verità morale. Esempi: Meglio un magro accordo che una grassa sentenza.

Massima $\rightarrow$ esprime una regola moraleggiante, un pricipio di condotta. Esempi:Uno che non sa governare sé stesso, come saprà governare gli altri?

Principio $\rightarrow$ stabilisce una norma o regola generale. Esempi: Non avere amici che non siano alla tua altezza.

Proloquio $\rightarrow$ contiene una regola, un precetto. Esempi: Tra moglie e marito non mettere il dito.

\section{L'origine dei proverbi}

L'origine della parola proverbio viene da proverbium, ossia, pro "davanti, prima" più verbum "parola". I proverbi apparirono per la prima volta in testi del XII secolo, ma fu Henri Estienne (1528-1598), nel 1579 all'incirca, chi firma uno dei più antichi studio sull'argomento e la più antica raccolta di proverbi appartiene all'inglese John Heywood (1497-1580), con la data del 1562 (XATARA, 2000, P. 13). Di ogni modo risulta quasi impossibile determinare il momento esatto in cui sono apparsi i proverbi e la sua utilizzazione, dato che, oltre il loro carattere animo, appartenevano a una tradizione orale, passavano da generazione a generazione tramite la voce dei piu anziani e, se furono registrati in qualche modo, questi documenti furono persi attraverso il tempo. Per diversi popoli dell'antichità, i proverbi furono utilizzati per incutere precetti moraleggianti e trasmettere concetti e idee filosofiche. Ci sono dei proverbi egiziani che datano di più di 2000 anni avanti Cristo, però, furono gli ebrei tramite la Scrittura Sacra, gli scrittori greci come Omero, Esiodo, Sofocle, Euripide, Eschilo, Platone, Aristotele, tra gli altri, e i 
Tradição oral e tradução: a comunicação intercultural e as dificuldades para a tradução-versão dos provérbios entre o português brasileiro e o italiano

Alcebíades Arêas

Edvaldo Sampaio Belizário

Maria Aparecida Cardoso Santos

latini, discepoli e seguitori dei greci, tra i quali Plauto, Terenzio, Lucrezio, Cicero, Virgilio, Orazio e Seneca che, tramite le loro opere, permetterono che essi fossero registrati e arrivassero fino a noi (LACERDA, p. XIX, 2004). A questo proposito, dice Albuquerque,

I 'sebayt' (insegnamenti), equivalenti ai proverbi attuali, vengono citati sin dal III millennio a.C. Tra gli Ebrei e gli Aramei, il proverbio rappresentava la parola di un saggio. Nel VI secolo a.C. sorgono le Parole di Abikar e, nel IV secolo a.C. i Proverbi di Salomone. Tra i Greci, 'gnòme' (pensiero) e 'paroemia' (istruzione) assumono la nozione di proverbio, sentenza, massima, adagio, precetto, ecc., nelle opere di Platone, Aristotele ed Eschilo. (ALBUQUERQUE, 1989, p. 35).

Possiamo, quindi, dire che l'anonimato attribuisce ai proverbi un carattere collettivo e non individuale, soprattutto quando pensiamo ai diversi flussi migratori che occorsero in tutto il mondo e nelle diverse epoche della storia dell'umanità. Sicuramente il contatto tra i popoli coinvolti in questo processo non restò immune delle influenze linguistiche, tra le quali risultò la cultura dei proverbi, facendo diventar quase impossibile, col passar dei tempi, il riconoscimento della loro origine. I proverbi traggono origine da tre fonti:

1) Classica: sono i proverbi di origine erudita provenienti dal latino come ad esempio: "Ne sutor ultra crepidam", citato da Plinio, l'Antico, in HistoriaNaturalis, la cui traduzione libera in italiano potebbre essere: "ognuno deve fare quello che se gli spetta"; oppure i biblici come questo: "Rendete dunque a Cesare quello che è di Cesare e a Dio quello che è di Dio" ( MATTEO, 22:21) con il quale Gesu avverte i suoi discepoli sul bisogno di compiere gli obblighi civili, pagando itributi; abbiamo ancora quelli di base filosofica come: "L'ignorante afferma, il saggio dubita, il sapiente riflette", da Aristotele; 
Tradição oral e tradução: a comunicação intercultural e as dificuldades para a tradução-versão dos provérbios entre o português brasileiro e o italiano

Alcebíades Arêas

Edvaldo Sampaio Belizário

Maria Aparecida Cardoso Santos

2) Letteraria: questa specie di proverbio corrisponde ugualmente al gruppo degli eruditi, che hanno la loro origine nella letteratura classica universale e sopravvisero al tempo; sono detti eternizzati da grandi personaggi storici, scrittori, filosofi, poeti, ecc, come ad esempio: "Sola la miseria è senza invidia nelle cose presenti" (IV Giornata, Introduzione, p. 129, Decameron, G. Boccacio); "Le parole fanno un effetto in bocca, e un altro negli orecchi."(I promessi sposi, A. Manzoni).

3) Popolare: questa sorta di proverbi solitamente nasce dalla saggezza popolare e ha forma e sapore caratteristici che rispecchiano nel loro insieme le usanze, i costumi, le abitudini, l'indole e la psicologia di una nazione. Essi costituiscono il gran numero di adagi, detti, sentenze, e s'immischiano nel folclore nazionale. Fra tanti esempi, possiamo citare: "Chi non muore si rivede"; "Acqua passata non macina più"; "A cuor non si comanda".

\section{Le caratteristiche dei proverbi}

I proverbi fanno parte della cultura e del folclore di un popolo e sono passati da generazione in generazione, direttamente, attraverso la parola. Esprimono verità universali e collettive e, generalmente, vengono usati dai più anziani che, basati su di essi, trasmettono autorità, insegnano, avvertono, rimproverano e danno consigli ai più giovani. Dato che appartengono alla tradizione orale di un popolo, essi trasmettono conoscenza e insegnamento sui più variati argomenti che coinvolgono la nostra vita: salute, lavoro, amicizia, amore, invidia, gelosia, lealtà, tradimento, egoismo, avarizia, avidità, prudenza, gioia, tristezza, morte, speranza. Perciò i proverbi hanno un valore moraleggiante e didattico che serve da strategia per le più diverse situazioni del quotidiano. Nel parere di Burker e Porter, 
Tradição oral e tradução: a comunicação intercultural e as dificuldades para a tradução-versão dos provérbios entre o português brasileiro e o italiano

Alcebíades Arêas

Edvaldo Sampaio Belizário

Maria Aparecida Cardoso Santos

Le persone usano i proverbi per dire alle altre quello che dev'essere fatto o quale atteggiamente assumere riguardo a una data situazione. Quindi, i proverbi sono "strategie per risolvere situazioni", ma strategie con autorità che formulano una parte del buon senso di una società, i suoi valori e il modo di fare le cose $(1997$, p. 45).

Una volta che sono presenti specialmente nella tradizione orale di un popolo, i proverbi hanno caratteristiche specifiche che facilitano la loro trasmissione. Sono generalmente concisi, ritmati e rimati perché vengano appresi più facilmente. Inoltre, essi possono avere un significato letterale, metaforico, eufemico, ludico e ironico nel momento in cui veicolano iloro messaggi moraleggianti.

Da quanto abbiamo detto prima, passiamo a individuare le seguenti proprietà che, di regola, vengono osservate nella composizione dei proverbi:

\section{La concisione}

I proverbi devono essere corti perché siano veicolati e appresi con più facilità dal parlante. Citiamo qualche esempio: A buon intenditor, poche parole. Chi disprezza, compra.

\section{I ricorsi fonologici}

Molti proverbi si avvalgono dei ricorsi fonologici, come il ritmo, la rima, l'allitterazione e l'assonanza per facilitare la sua memorizzazione e propagazione tra le diverse generazioni. Per illustrare, citiamo: Chi non risica, non rosica.Chi di spada ferisce, di spada perisce.Lontano dagli occhi, lontano dal cuore.

\section{I ricorsi sintatici}


Tradição oral e tradução: a comunicação intercultural e as dificuldades para a tradução-versão dos provérbios entre o português brasileiro e o italiano

Alcebíades Arêas

Edvaldo Sampaio Belizário

Maria Aparecida Cardoso Santos

Le citazioni proverbiali vengono espresse col verbo nel presente del modo indicativo con lo scopo di suggerire il suo carattere atemporale. Si trova anche dei casi in cui si adoperano il modo imperativo, quando si intende di dare un consiglio, di veicolare una regola oppure una legge. I proverbi si servono anche dei parallelismi, ripetizioni e strutture bipartite per facilitare le loro assimilazione. Vediamo degli esempi: Non è bello ciò che è bello ma è bello ciò che piace. Va con chi è meglio di te e pagagli le spese.L'occhio è lo specchio dell'anima. Occhio per occhio, dente per dente.

\section{I ricorsi lessicali}

Di solito, i proverbi vengono formati da parole di origine popolari, poiché, parimente ad altri ricorsi prima citati, favoriscono l'intendimento e la memorizzazione dalla parte dei parlanti: Non c'è fumo senza arrosto. Ad ognuno la sua croce.L'erba del vicino è sempre più verde.

Molto spesso, i proverbi popolari subiscono delle variazioni con l'inserzione di parole della mala lingua al posto di altre meno grossolane. L'artificio viene utilizzato, in alcuni casi, con l'obiettivo di far sì che il proverbio abbia un carattere più offensivo e di forte impatto: Quando l'acqua tocca il culo s'impara a nuotare. Chi ben s'inchina offre il culo.

C'è anche l'uso dei proverbi che sono arcaici per quel che si rifesce al vocabolario o al costrutto. Però, l'uso di arcaismi non elimina il carattere coloquiale del proverbio; al contrario, rinforza le sue caratteristiche proprie della saggeza universale. Nei due esempi che seguono abbiamo il proverbio nella forma arcaica e il suo corrispondente nella forma più moderna:L'avidità rompe il sacco corrisponde a Chi tutto vuole nulla stringe; e All'arca aperta il giusto vi peccacorrisponde a L'occqasione fa l'uomo ladro.

\section{Il carattere universale del messaggio}


Tradição oral e tradução: a comunicação intercultural e as dificuldades para a tradução-versão dos provérbios entre o português brasileiro e o italiano

Alcebíades Arêas

Edvaldo Sampaio Belizário

Maria Aparecida Cardoso Santos

I proverbi sono delle sentenze di carattere universale che contengono dei sappienti consigli e insegnano dei principi e delle condotte che si applicano alle più varie culture diffuse nel mondo. Molti dei proverbi vengono tradotti in lingue diverse, facendo sì che la sua universalità e applicabilità si propaghino in diverse culture. Il proverbio di origine latina Qui tacet, consentire videtur, diffuso da Bonifacio VIII, papa tra il 1294 e 1303, possiede una versione in varie lingue:

Chi tace acconsente. (italiano)

Quem cala, consente. (português)

Quien calla ortoga. (espanbol)

Silence gives consent. (inglês)

Qui ne dit mot consent. (francês)

Cine tace, aproba. (romeno)

Werschweigt, stimmt乏u (alemão)

Possiamo comunque trovare, con minore frequenza, dei proverbi che non possiedono equivalenti in altre lingue perche riflettono tipicamente un'atmosfera singolare della cultura nella quale sono nati. Claudia Maria Xatara e Thais Marini Succi ${ }^{10}$, affermmano che il detto popolare brasiliano: "Chi non ama il samba non è una buona persona, è marcio nella testa o malato nei piedi" (in portoghese: Quem não gosta de samba, bom sujeito não é, é ruim da cabeça ou doente do pé) è un tipo di sentenza che non si può dire in un'altra cultura tranne la brasiliana. Ciò conferma l'idea della particolarità che hanno certi proverbi riguardo il locale della loro difusione.

${ }^{10}$ XATARA, Claudia Maria e SUCCI, Thais Marini. Revisitando o conceito de provérbio, p. 38. Disponível em: http://www.ufff.br/revistaveredas/file/2009/12/artigo31.pdf. Acesso em 12 out 2018. 
Tradição oral e tradução: a comunicação intercultural e as dificuldades para a tradução-versão dos provérbios entre o português brasileiro e o italiano

Alcebíades Arêas

Edvaldo Sampaio Belizário

Maria Aparecida Cardoso Santos

\section{Il carattere moraleggiante e didattico}

I proverbi ci portano all'educazione morale e chi li usa intende trasmettere al suo intenditore un'autorità propria della saggeza universale. Malgrado i proverbi siano un patrimonio della colettività, quando vengono usati, riflettono l'intenzione moraleggiante e didattica di quelli che li citano e servono a risolvere problemi quotidiani che mettono in conflitto l'armonia collettiva. Perciò, i proverbi hanno il potere di insegnare, di consigliare, di incentivare, di avvertire, di intimidare, di far riflette, di rimproverare, di consolare, di orientare:

Dimmi con chi vai e ti dirò chi sei. (avvertenza)

La fretta è cattiva consigliera. (saggerza)

Dopo la tempesta torna sempre il buon tempo. (consolazione)

Chi va piano va sano e va lontano. (insegnamento)

Chi la fa, l'aspetti. (minaccia)

Fai quello che dico, ma non fare quello che faccio.(orientazione)

Non tutto il male vien per nuocere. (riflessione)

Chi dice ciò che vuole può sentire ciò che non vorrebbe. (rimprovero)

\section{Il grande potere comunicativo}

In virtù della loro concisione, della loro facilità da memorizzare e della diffusione di conoscenze comuni sui più diversi aspetti della vita quotidiana, $\mathrm{i}$ proverbi hanno una grande capacità comunicativa. Chi adopera un proverbio, riesce a comunicare con rapidità e chiarezza. La estesa spiegazione che viene implicita nel proverbio non è necesaria, dato che la conoscenza del contenuto 
Tradição oral e tradução: a comunicação intercultural e as dificuldades para a tradução-versão dos provérbios entre o português brasileiro e o italiano

Alcebíades Arêas

Edvaldo Sampaio Belizário

Maria Aparecida Cardoso Santos

del messaggio viene condiviso da tutti i membri della società in cui viene usato. Dunque, se vogliamo dire a qualcuno che la prudenza ci raccomanda di accontentare con quello che abbiamo conseguito e non rischiare tutto credendo di averne di più, ci conviene, usare il proverbio "Meglio un novo oggi che una gallina domani", una volta che la sua capacità di comunicare è molto più efficace e produttiva. E ancora, se vogliamo consigliare qualcuno, adoperando una ideia opposta alla prudenza, la lunga spiegazione potrebbe essere sostituita dal breve proverbio "Chi non risica, non rosica".

\section{Il ricco contenuto semantico}

Dal suo forte contenuto semantico, i proverbi discorrono sui più vari argomenti che coinvolgono la vita: salute, lavoro, amicizia, invidia, gelosia, lealtà, tradimento, egoismo, avarizia, avidità, prudenza, gioia, tristezza, morte, speranza. Esprimono più opinioni generali che personali, le quali vengono approvate dalla società, visto che non appartengono a questo o a quello membro ma a tutti quanti.Vediamo alcuni esempi: Chi dorme non piglia pesce (lavoro); Amore con amore si paga (amore); Chi troppo vuole nulla stringe (ganância); Uomo avvisato mezzo salvato (prudenza); Finché ceè vita c'è speranza (speranza).

\section{La costituzione letterale}

Il carattere letterale avviene quando le parole che compongono i proverbi non esigono un'interpretazione metaforica per la comprensione del messaggio, dell'avvertenza, del consiglio che ci inseriscono. Pochi sono i proverbi che hanno questa caratteristica e, anche in questi casi, possiamo darle, se ci conviene, un significato metaforico: Non fare agli altri ciò che non vorresti fosse fatto a te; Le disgrazie non vengono mai sole. 
Tradição oral e tradução: a comunicação intercultural e as dificuldades para a tradução-versão dos provérbios entre o português brasileiro e o italiano

Alcebíades Arêas

Edvaldo Sampaio Belizário

Maria Aparecida Cardoso Santos

\section{La costituzione metaforica}

Diciamo che il proverbio ha una costituzione metaforica quando le immagini che vengono espresse in esso ci portano a un'interpretazione che va oltre il significato letterale delle parole che lo compongono. La maggior parte dei proverbi riesce a comunicarsi attraverso il linguaggio connotato, cioè, il proverbio deve essere capito a partir da quello che il messaggio suggerisce: $C h i$ va con lo zoppo impara a roppicare (Si prendono le abitudini, specie negative, di quelli che si frequentano); Chi va piano va sano e va lontano (pian piano si raggiunge un obiettivo); Una volta corre il cane e una volta la lepre (La buona e la cattiva sorte arrivano alternandosi); Una rondine non fa primavera (Per le grandi trasformazioni occorre la partecipazione di molte persone); Di notte tutti $i$ gatti sono bigi (Al buio tutte le cose hanno la stessa sembianza).

\section{L'aspetto ludico e umoristico}

Anche l'umore e la creatività sono presenti nella cultura proverbiale, specialmente quando parliamo dei famosi controproverbi che sono le variazioni dei proverbi tradizionali. "Chi non ha cane caccia con maiale", direbbe uno spiritoso qualunque per fare diventar divertente il proverbio. L'utilizzo di questo aspetto ludico-umoristico dei proverbi può essere osservato dal titolo della pièce "Chi ride l'ultimo è bionda o portoghese" (in portoghese: Quem ri por último é loira ou português), dell'umorista brasiliano Jorge Paulo, che è una variazione scherzosa del famoso proverbio Ride bene chi ride l'ultimo. Altri esempi sono: Il miglior attacco è la difesa; Guarda prima di saltare; Chi esita è perduto; Molte mani fanno un lavoro leggero; Troppi cuochi rovinano il brodo. 
Tradição oral e tradução: a comunicação intercultural e as dificuldades para a tradução-versão dos provérbios entre o português brasileiro e o italiano

Alcebíades Arêas

Edvaldo Sampaio Belizário

Maria Aparecida Cardoso Santos

\section{Il carattere ironico}

In comunione con l'aspetto ludico-umoristico dei proverbi si verifica la caratteristica ironica che molti di essi possiedono. Di solito i proverbi con valore ironico sono di origine sconosciuta, poiché sono i risultati di uno sguardo critico che cerca, di qualunque maniera, di annullare gli insegnamenti venuti dalle esperienze collettive transmesse da molte generazioni, sostituendoli da nuovi concetti che si oppongonoao tradizionale pensiero collettivo. Come esempio, possiamo citare lo scrittore brasiliano Guimarães Rosa, nelle cui opere incontriamo innumerevoli esempi di proverbi con valore ironico. Per citarne un esempio, ricordiamo qui l'aforismo "Vivere è uno affare molto pericoloso" che viene citato qualche volta nel suo libro Grande Sertão: Veredas. Il proverbio dello scrittore del MinasGerais è una evidente ironia che si contrappongono a proverbi del tipo: "La vita è bella"; "Vivere è fantastico"; "Vivere è un regalo di Dio"; "Vivere è ricordare". Vediamo altri esempi: Se vai con to roppo, aspettalo; Non è bello ciò che è bello, figuriamoci ciò che è brutto; Gallina vecchia si fa il lifting; Quando si chiude una porta, tu rimani fuori; Chi troppo vuole nulla rifiuta; Can che abbaia non dorme.

\section{La funzione eufemistica}

Come abbiamo già accennato prima, i proverbi hanno un valore moraleggiante e didattico e, perciò, vengono molte volte utilizzati per dare un consiglio preventivo. Ma, rinforzata specialmente dal carattere metaforico dei proverbi, l'ammonimento funziona da eufemismo, cioè serve a veicolare, trasmettere una notizia, un'informazione in maniera meno sgradevole. Il proverbio "Chi dice quel che vuole, sente quel che non vorrebbe", è un esempio utilizzato per evitarsi una avvertenza molto diretta e pesante del tipo: "Se 
Tradição oral e tradução: a comunicação intercultural e as dificuldades para a tradução-versão dos provérbios entre o português brasileiro e o italiano

Alcebíades Arêas

Edvaldo Sampaio Belizário

Maria Aparecida Cardoso Santos

maledice qualcheduno, riceverà cose peggiori", facendo in modo che il rimprovero sia più soave e meno sconvolgente.

\section{Gli antiproverbi}

Gli antiproverbi sono delle piccole variazioni dei proverbi tradizionali che, in modo ludico e sarcastico, corrompono il significato originale dei messaggi moraleggianti che essi rivelano. Perché un antiproverbio venga creato, è molto importante che si conosca il suo significato, affinche si possa invertire il suo senso e crearne un altro. Quando qualcuno crea un antiproverbio, elimina dalla sentenza originale il significato moraleggiante, attribuendo ad essa un valore nuovo e spiritoso. Alcuni esempi di antiproverbi sono: Chi va piano va sano, ma viene tamponato poco lontano; Can che abbaia lo sbattono fuori dal condominio; Chi di spada ferisce gli danno dieci anni senza codizionale; Chi dorme non piglia sonniferi; Chi fa da sé si sente solo.

\section{Alcuni detti popolari e le loro dovute correzioni}

Alcuni detti popolari, passati da generazione a generazione, perdono il loro significato di base che viene rinnovato dalla tradizione orale. Questi detti hanno delle origini remote e, molte volte, il suo significato di base viene ignorato dalle persone che se ne utilizzano. Non è compito facile indicare le cause di queste alterazioni e il momento in cui cominciarono ad accadere, ma possiamo dire che parte di queste modificazioni si è effetuata dovuto alle prossimità sonore delle parole o dall'interpretazione equivocata del significato originale di esse. Citiamo alcuni esempi di detti popolari che hanno avuto la sua origine con significato diverso da quello che abbiamo oggigiorno: Ognuno tira la barca al proprio mulino (detto originale: Ognuno tira l'acqua al suo mulino); 
Tradição oral e tradução: a comunicação intercultural e as dificuldades para a tradução-versão dos provérbios entre o português brasileiro e o italiano

Alcebíades Arêas

Edvaldo Sampaio Belizário

Maria Aparecida Cardoso Santos

Tanto va la gatta al lardo che ci lascia lo zampillo (detto originale: Tanto va la gatta al lardo che ci lascia lo zampino).

\section{Una proposta per la traduzione dei proverbi nel contesto delle lingue portoghese brasiliana e italiana}

Chi si propone a tradurre si domanda spesso se deve fare una traduzione più letterale, parola per parola, oppure decidere di eseguire una traduzione libera. A dire il vero, non esiste una traduzione cento per cento libera o letterale. Chi traduce deve sempre prendere in considerazione siano le caratteristiche della lingua source, siano quelle della lingua target, affinché venga evitato qualunque specie di adulterazione del messaggio.

Nell'enunciato "Gli azzurri hanno vinto quattro campionati mondiali di calcio", la parola "azzurro"acquisisce una connotazione specifica dell'italiano perché si riferisce a tutta la squadra, cioè, a tutti i calciatori che appartengono alla squadra nazionale di uno sport in particolare. Nell'enunciato sopraccitato, il riferimento al calcio viene espresso nel costrutto "quattro campionati di calcio". Gli "azzurri" sono i calciatori che difendono i colori della loro squadra, in questo caso la nazionale italiana, la cui maglia è predominantemente azzurra. Comunque, in un altro contesto, la parola "azzurro" non avrà la stessa forza espressiva. Per esempio, se facciamo riferimento al colore degli occhi di una persona, non possiamo adoperarla da sola perché il colore non può sostituire "gli occhi", ma accompagnarli e qualificarli. Quindi, in italiano non sarebbe possibile dire "Gli azzurri di Anna sono affascinanti" senza esprimere la parola che l'aggettivo "azzurri" qualifica.

L'espressione italiana "zucchero filato", formata dalle parole "zucchero" e "filato", che in portoghese, significa rispettivamente,"açúcar" e "em fios", corrisponde all'espressione portoghese "algodão-doce". Quindi, come possiamo 
Tradição oral e tradução: a comunicação intercultural e as dificuldades para a tradução-versão dos provérbios entre o português brasileiro e o italiano

Alcebíades Arêas

Edvaldo Sampaio Belizário

Maria Aparecida Cardoso Santos

vedere, nella traduzione dell'espressione, dall'italiano al portoghese, non adottiamo il metodo letterale, parola per parola, perché risulterebbe strano, e pure incomprensibile, ad un lettore di lingua madre brasiliana il costrutto "açúcar em fios". Infatti, l'espressione italiana si riferisce al materiale e al modo come viene fatto questa leccornia (zucchero filato); in portoghese però l'espressione "algodão-doce" fa riferimento all'apparenza e al sapore della goloseria. Ciò dimostra, pertanto, quanto sia "difficile elaborare un codice o un manuale di traduzione. Le possibili applicazioni di una parola sono innumerevoli ed imprevedibili" "11 (RÓNAI, 1981, p. 19). Il traduttore deve essere sempre vigile al fine di interpretare e di offrire una buona soluzione per le complesse situazioni che si presentino. E pertanto si deve appoggiare in un solido bagaglio culturale in ambedue le lingue con cui lavora.

Nel rapporto tra due lingue c'è anche la differenza formale. Non di rado ci sono nella lingua source delle parole inesistenti nella lingua target, è anche frequente i casi in cui c'è una parola con diverse accezioni. Prendiamo in considerazione, ad esempio, la parola italiana "nipote" che in portoghese viene tradotta sia come "neto", sia come "sobrinho". Un'altro esempio interessante da prendere in esame riguarda ai verbi "levar" e "trazer" che in portoghese hanno una netta distinzione mentre in italiano non ci sembra affatto chiara, poiché si usa in situazioni diverse lo stesso "portare" come si vede in: 1) Che cosa mi hai portato da Roma? (in portoghese: O que me trouxe de Roma?); 2) Porto i bambini a scuola.(in portoghese: Levo as crianças para a escola.).

Un altro esempio abbiamo nella parola italiana "cacciavite", la cui traduzione in portoghese è "chave de fenda", la quale porta in sé una ricchezza espressiva a causa del verbo "cacciare" che può significare in portoghese sia

${ }^{11} \mathrm{La}$ traduzione è nostra. 
Tradição oral e tradução: a comunicação intercultural e as dificuldades para a tradução-versão dos provérbios entre o português brasileiro e o italiano

Alcebíades Arêas

Edvaldo Sampaio Belizário

Maria Aparecida Cardoso Santos

"introduzir" che "retirar", che sono le funzioni proprie di quest'arnese. Quindi, abbiamo: "caccia" = introduv, retira e "vite" = parafuso.

Quando lavoriamo con traduzione, non possiamo fare a meno delle questioni di carattere stilistico, legate strettamente alla produzione del discorso. La scelta della parola, come ad esempio: Andare dal benzinaio[frentista] (in portoghese: Irao posto de gasolina); la posizione della parola nel discorso: Sono già le nove(in portoghese: Lásão nove horas); Carla è una mia amica(in portoghese: Carla è umaamigaminha); la combinazione delle parole: Io mi mangio una mela(in portoghese:Eu comoumamaça); la forma verbale: Divento professore (in portoghese:Torno-me professor); L'autobus si ferma (in portoghese:O ônibus para); la regenza verbale: Conto sui miei genitori (in portoghese:Conto commeuspais); Vado a bere un bicchiere d'acqua(in portoghese:Voubeberumcopo de água); Mi piace parlare italiano(in portoghese:Gosto de falar italiano), ecc. A questo punto ci pare interessante la formula: tradurre nella forma più letterale possibile, ma farlo con tutta la libertà possibile.

Ogni parola tradotta è intimamente legata al contesto generale del testo. La traduzione di una parola isolata dal contesto in cui viene inserita non è che una pretenziosa illusione. Perché una traduzione sia credibile, la parola deve essere inserita in una frase; essa deve inserirsi nel capoverso e quest'ultimo si deve inserire in tutto il testo. L'eterno dilemma di chi traduce consiste in dire quello che dice l'autore del testo source oppure quello che egli vuole esprimere. Nella prima ipotesi, si direbbe che la traduzione risulta più o meno letterale e il lettore deve interpretare quello che è scritto; nella seconda, invece, l'interpretazione è fatta dal traduttore ed il lettore riceve un lavoro più comprensibile, però meno fedele all'originale. Inoltre, nella prima ipotesi si rischia di perdere il concetto che l'autore voleva esprimere, mentre, nell'altro, 
Tradição oral e tradução: a comunicação intercultural e as dificuldades para a tradução-versão dos provérbios entre o português brasileiro e o italiano

Alcebíades Arêas

Edvaldo Sampaio Belizário

Maria Aparecida Cardoso Santos

si rischia di far dominare il punto di vista del traduttore e non quello dell'autore.

Per quel che concerne i proverbi in modo particolare, bisogna ricordare che, per sintetizzare un concetto attinente alla realtà oppure a una regola sociale e morale, essi devono avere una traduzione che trascenda i limiti del lessico, facendo a meno della traduzione comunicativa in vantaggio di quella semantica; e cioè, per diventare quello che chiameremmo di "traduzione culturale".

Dato che esprimono la sapienza e la cultura di un popolo, i proverbi non possono, e soprattutto non devono, essere tradotti in maniera diretta, letterale, poiché una procedura siffatta può rappresentare un rischio per l'essenza dei loro significati. Invero, quando traduciamo un proverbio, dobbiamo cercar di trovare un equivalente nella lingua target, indipendentemente se esso s'avvicina o s'allontana dal lessico, preservando, comunque, il suo messaggio moraleggiante. Dunque, quel che si traduce, o si deve tradurre, non è l'insieme delle parole che forma il proverbio, ma il suo senso moralizzatore, indipendente della simmetria o dissimmetria lessicale con l'equivalente della lingua source.

Tra il proverbio brasiliano: "Um dia da caşa, outro do caçador" e l'equivalente italiano: "Una volta corre il cane e un'altra la lepre"non esiste nessuna somiglianza dal punto di vista lessicale. Il senso moraleggiante però è lo stesso, cioè si equivalgono: oggi siamo fortunati oppure vinciamo; domani seremo sfortunati oppure perdiamo. Già nell'esempio: "Em briga de marido e mulher não se mete a colher", possiamo osservare una parziale somiglianza nel confronto dell'equivalente italiano: "Tra moglie e marito non mettere il dito", nel quale avviene l'inversione dei termini "marido" e "mulher" (moglie e marito) nell'inizio del proverbio e, alla fine, vengono usati sostantivi diversi: "colher" e 
Tradição oral e tradução: a comunicação intercultural e as dificuldades para a tradução-versão dos provérbios entre o português brasileiro e o italiano

Alcebíades Arêas

Edvaldo Sampaio Belizário

Maria Aparecida Cardoso Santos

"dito", per la necessità della rima. Comunque, anche in questo esempio, l'effetto moraleggiante del messaggio è lo stesso, ossia, non dobbiamo immischiarci nelle liti coniugali. C'è ancora dei casi in cui tra i proverbi nel confronto portoghese brasiliano-italiano accade una somiglianza lessicale integrale. In questo paio di lingua in specifico, questa somiglianza integrale succede perché le due lingue hanno la stessa origine, cioè il latino, dalla cui cultura linguistica provengono la maggior parte dei proverbi. Ad esempio, abbiamo il proverbio "Cão que ladra não morde", il cui equivalente italiano è "Can che abbaia non morde". In questo esempio possiamo osservare un'analogia riguardo alla scelta delle parole e lo stesso senso moraleggiante: chi proferisce molte minacce di solito non passa ai fatti. Talvolta la scelta del proverbio equivalente dell'altra lingua può seguire criteri che rispettino l'identità culturale piuttosto che la somiglianza lessicale. Il proverbio italiano "Chi dorme non piglia pesce" ha nella lingua portoghese l'equivalente "Quem dorme, não pega peixe", ma il proverbio "Deus ajuda quem cedo madruga", che ha una formazione lessicale diversa, sembra trasmettere meglio il messaggio morale di questa massima, cioè, "chi è pigro e sfaticato si lascia sfuggire le buone occasioni".

Nel momento in cui si traduce um proverbio, non si può tradire il suo senso morale a nome di un rigore di carattere lessicale. Parecchie volte un insieme di parole di una certa lingua non crea un effetto oppure un messaggio morale che possa essere capito in un altro contesto culturale. Perciò il traduttore che si trova davanti a un proverbio deve cercare nella lingua per cui sta traducendo un corrispondente con lo stesso valore per utilizzarlo nel testo che sarà tradotto. Anche nei casi in cui non c'è equivalenza tra le due lingue in confronto, il traduttore dev'essere molto meticoloso nel momento di tradurre un proverbio, facendo, quindi, una ricerca attenta sopra l'appliccabilità delle 
Tradição oral e tradução: a comunicação intercultural e as dificuldades para a tradução-versão dos provérbios entre o português brasileiro e o italiano

Alcebíades Arêas

Edvaldo Sampaio Belizário

Maria Aparecida Cardoso Santos

parole nel contesto culturale di ogni lingua, affinché l'effetto moraleggiante non perda mai la sua essenza.

Sono innumerevoli $\mathrm{i}$ proverbi in portoghese brasiliano che hanno un equivalente in italiano, sia per la dissomiglianza, per somiglianza parziale che totale. Per esempio citiamo: À casa de tua tia, não vás todo dia / Ospite raro ospite caro, A fome é má conselheira / La fame è cattiva consigliera, À noite todos os gatos são pardos / Al buio tutti i gatti sono bigi, A união faz a força / L'unione fa La forza, Água mole em pedra dura, tanto bate até que fura / A goccia a goccia si scava la pietra, $A$ mentira tem pernas curtas / Le bugie hanno le gambe corte, Antes tarde do que nunca / Meglio tardi che mai, Cada um por si e Deus por todos / Ognuno per sé e Dio per tutti, Com fogo não se brinca / Col fuoco non si scherza, De grão em grão a galinha enche o papo (também Devagar se vai longe) / Chi va piano va sano e va lontano, Dizei-me com quem andas e eu te direi quem és / Chi va con lo zoppo, impara a zoppicare, É melhor prevenir do que remediar / Prevenire è meglio che curare, Em boca fechada não entra mosca / In bocca chiusa non entrano mosche, Em casa de ferreiro, espeto de pau / In casa del fabbro spiedo di legno, Enquanto há vida, há esperança / Finché c'è vita, c’è speranza, Falar é fácil, fazer que é difícil / Tra il dire e il fare c'è in mezzo il mare, Fazo que eu digo, mas não faças o que eu faço / Fa quel Che il prete dice, non quel Che il prete fa, Gosto não se discute / Tutti i gusti son gusti, Mais vale um pássaro na mão do que cem voando / Meglio l'uovo oggi che la gallina domani, Nada como um dia após o outro / La notte porta consiglio, Não conte com o ovo na barriga da galinha / Non vendere la pelle dell'orso prima di averlo ucciso, Onde há fumaça, bá fogo / Non c'è fumo senza arrosto, Os últimos serão os primeiros / Gli ultimi saranno i primi, Panela velha é que faz comida boa / Gallina vecchia fa buon brodo, Quando o gato sai, os ratos fazem a festa / Quando il gatto non c'è $i$ topi ballano, Quem avisa, amigo é / Uomo avvisato mezzo salvato, Quem cala, consente / Chi tace acconsente, Quem não arrisca, não petisca / Chi non risica non rosica, Quem tudo quer, tudo perde / Chi troppo vuole nulla stringe, Toda regra tem exceção / Non c'è regola 
Tradição oral e tradução: a comunicação intercultural e as dificuldades para a tradução-versão dos provérbios entre o português brasileiro e o italiano

Alcebíades Arêas

Edvaldo Sampaio Belizário

Maria Aparecida Cardoso Santos

senza eccezioni, Uma desgraça nunca vem só / Le disgrazie non vengono mai sole, Uma andorinha só não faz verão / Una rondine non fa primavera.

\section{Conclusione}

Da quanto è stato visto in questo articolo, riteniamo che la presenza di proverbi, massime, frasi e aforismi - tra le altre forme presentate - sia importante nella formazione culturale delle persone, specialmente per quanto riguarda il mantenimento della memoria sociale dei popoli e il valore della tradizione orale. Inoltre, sono fondamentali nel consolidamento dei valori morali e dei principi di convivenza sociale perché contengono, a volte in modo implicito, consigli che indicano modi di vivere bene, di vivere in armonia, di non estrapolare i limiti e le limitazioni delle persone con chi viviamo insieme. In altre parole, i proverbi e tutte le forme che lo seguono hanno un valore pedagogico e didattico importante e indiscutibile che si fissa nella memoria e finisce per fungere da codice di condotta.

La forma concisa e l'uso di parole semplici con una struttura logica di facile comprensione consentono di memorizzare e trasmettere le formule proverbiali con facilità a prescindere dal loro utilizzo, dal momento che non è sempre facile evitare che la gente tenti di togliersi la polvere dai propri occhi senza badare alle proprie palpebre.

È importante sottolineare, anche a rischio di essere ripetitivi, che una caratteristica importante dei costrutti proverbiali è il loro carattere di universalità. In realtà, queste forme non trovano limiti o conoscono barriere sociali, ideologiche o geografiche. Al contrario, sono presenti in tutti i paesi e in tutte le culture del mondo le cui persone, a prescindere dalla classe sociale o dall'appartenenza politico-ideologica, hanno una grande responsabilità di mantenerle vive attraverso ripetizioni e aggiornamenti. 
Tradição oral e tradução: a comunicação intercultural e as dificuldades para a tradução-versão dos provérbios entre o português brasileiro e o italiano

Alcebíades Arêas

Edvaldo Sampaio Belizário

Maria Aparecida Cardoso Santos

Ed è proprio questa capacità di ripetizione e aggiornamento che attribuisce importanza allo studio dei proverbi e delle loro manifestazioni. Il presente lavoro presenta solo una parte di un progetto molto più ampio e la sua importanza, quando fa l'analisi contrastiva tra i proverbi prodotti in lingua portoghese e quelli prodotti in italiano, consiste non solo nell'arricchimento degli studi di traduzione, ma nella segnalazione agli altri che c'è ancora molto da fare in questo campo.

\section{Riferimenti bibliografici}

ALBUQUERQUE, Maria Helena Trench de. Um exame pragmático do uso de enunciados proverbiais nas interpretações verbais correntes. São Paulo: Universidade de São Paulo, 1989.

BURKE, Peter e PORTER, Roy. História social da linguagem. Trad. Alvaro Hattnher. São Paulo: Fundação Editora da UNESP, 1997.

BURKE, Peter \& PORTER, Roy. História social da linguagem. Trad. Álvaro Hattnher. São Paulo: UNESP, 1997.

CHIESA, Carlo Felice \& BERTOZZI, Lamberto. Il secolo azzurro: 1910-2010. Bologna: Minerva Edizioni, 2011.

LACERDA, Roberto Cortes de, LACERDA, Helena da Rosa Cortes de e ABREU, Estela dos Santos. Dicionário de provérbios: francês, português, inglês. $2^{\text {a }}$ ed. São Paulo: Editora UNESP, 2004.

RÓNAI, Paulo. $A$ tradução vivida. $2^{a}$ ed. Rio de Janeiro: Nova Fronteira, 1981.

XATARA, Cláudia Maria e OLIVEIRA, Wanda Leonardo de. Dicionário de provérbios, idiomatismos e palavrôes: francês-português/português-francês. São Paulo: Cultura, 2002.

XATARA, Claudia Maria e SUCCI, Thais Marini. Revisitando o conceito de provérbio. http://www.ufjf.br/revistaveredas/file/2009/12/artigo31.pdf. Acesso em 12 out 2016. 